\title{
Chapter 13 \\ The Spatial Distribution of Radiocesium \\ Over a Four-Year Period in a Forest Ecosystem in North Fukushima After the Nuclear Power Station Accident
}

\author{
Masashi Murakami, Takahiro Miyata, Natsuko Kobayashi, Keitaro Tanoi, \\ Nobuyoshi Ishii, and Nobuhito Ohte
}

\begin{abstract}
We have investigated the redistribution dynamics of radiocesium deposited after the nuclear power station accident in March 2011 in a forested catchment located in North Fukushima over a four-year period (2012-2015). At the catchment scale, ${ }^{137}$ Cs accumulation decreased drastically by $50 \%$ of the estimated initial accumulation during the first 2 years. Cs-137 accumulation in the forest floor occurred in the litter layers and the surface part of mineral soils and have accounted for about $90 \%$ of the total catchment scale accumulation. The internal ${ }^{137} \mathrm{Cs}$ cycle among the soil-plant system was also identified as a retention mechanism and was biologically dynamic. Monitoring the decreasing and retaining mechanisms of radioactivity at the ecosystem scale will be required for effective forest and water resource management.
\end{abstract}

Keywords ${ }^{37} \mathrm{Cs} \cdot$ Inventory $\cdot$ Environmental half-life $\cdot$ Forest ecosystem $\cdot$ Internal cycle $\cdot$ Fukushima

M. Murakami · T. Miyata

Graduate School of Science, Chiba University, Chiba, Japan

N. Kobayashi $\cdot$ K. Tanoi

Graduate School of Agricultural and Life Sciences, The University of Tokyo, Tokyo, Japan

N. Ishii

National Institute of Radiological Sciences, Chiba, Japan

N. Ohte $(\bowtie)$

Department of Social Informatics, Graduate School of Informatics, Kyoto University,

Kyoto, Japan

e-mail: nobu@i.kyoto-u.ac.jp 


\subsection{Introduction}

The explosions at the Fukushima Daiichi Nuclear Power Station in March 2011 released a large amount of radioactive materials, especially iodine $\left({ }^{131} \mathrm{I}\right.$ and $\left.{ }^{133} \mathrm{I}\right)$ and cesium $\left({ }^{134} \mathrm{Cs}\right.$ and ${ }^{137} \mathrm{Cs}$ ), into the environment (Chino et al. 2011; Steinhauser et al. 2014). Half-lives of ${ }^{131} \mathrm{I}$ and ${ }^{133} \mathrm{I}$ are only 8.03 days and $20.8 \mathrm{~h}$, respectively, but the half-lives of ${ }^{134} \mathrm{Cs}$ (2.07 years) and ${ }^{137} \mathrm{Cs}$ (30.1 years) are longer. Because of the long half-life of ${ }^{137} \mathrm{Cs}$, it is expected that ${ }^{137} \mathrm{Cs}$ will pollute the surrounding natural environment for many years into the future.

About $70 \%$ of the Fukushima prefectural territory is covered by forests. The local communities have traditionally utilized the forests extensively not only for timber production but also for firewood and charcoal production before the 1960s. The collection of edible wild plants and mushrooms have also been a part of the traditional lifestyle of the residents for a very long time. It has been wildly recognized in Japan that local people have generally respected the environment and products of the forest ecosystem of this region (Fukushima Prefecture 2017). Therefore, it is critical for local people to precisely understand the quantity and distribution of radiocaesium in the forests and surrounding environment.

The first phase of the governmental surveys revealed that a major portion of the deposited radiocesium was trapped in the canopy of coniferous forests and in the litter layer on the forest floor of deciduous forests (Ministry of Education, Culture, Sports, Science and Technology; Ministry of Agriculture, Forestry and Fisheries 2012; Hashimoto et al. 2012). Within the forest ecosystem, radioactive materials deposited on the tree canopies subsequently moved to the forest floor by precipitation (Kinnersley et al. 1997; Kato et al. 2012) and litter fall (Bunzl et al. 1989; Schimmack et al. 1993; Hisadome et al. 2013). The movement of radiocesium from the canopy to the forest floor has gradually decreased (Hashimoto et al. 2013). Radiocesium has been shown to be easily adsorbed by clay minerals and soil organic matter (Kruyts and Delvaux 2002), which can be transported by eroded soil, particulates, and dissolved organic matter through hydrological channels, streams, and rivers (e.g., Fukuyama et al. 2005; Wakiyama et al. 2010).

Dissolved radiocesium, which is relatively free from soil adsorption, can also be taken up by microbes, algae, and plants in soils and aquatic ecosystems. By propagating through the food web in the forest ecosystem, it was expected that radiocesium would eventually be introduced into insects, worms, fish, birds and mammals. Many previous reports on the distribution and transfer of radionuclides have focused on their bioaccumulation and the transition between trophic levels (Kitchings et al. 1976; Rowan and Rasmussen 1994; Wang et al. 2000).

Our four-year monitoring study since early 2012 at a forested headwater catchment in the northern part of Fukushima have demonstrated that radiocesium movement has been most drastic during the early years after the accident (Ohte et al. 2013, 2016). Observed results have shown that radiocesium has continuously moved from the forest canopies to the forest floor with throughfall, stemflow and litter fall 
(Endo et al. 2015). It was found that fallen leaves and throughfall waters in the deciduous tree stands contain a certain amount of radiocesium since 2012. Since the attachment of deposited radiocesium did not occur directly onto leaves at the time of the accident in March 2011, because deciduous trees did not have new leaves, radiocesium inclusion in leaves in 2012 indicated that the translocation of radiocesium occurred in leaves from within the tree body (Endo et al. 2015). One of the possible sources of radiocesium transported to leaves was the deposited radiocesium in the litter layer on the forest floor. ${ }^{137} \mathrm{Cs}$ in the organic layers (i.e, $\mathrm{L}, \mathrm{F}$ and $\mathrm{H}$ horizons) of the deciduous stands ranged from 15 to $50 \mathrm{KBq} \mathrm{m}^{-2}$; these organic layers were the largest compartment where ${ }^{137} \mathrm{Cs}$ accumulated in the forest ecosystem (Murakami et al. 2014). For radiocesium to be transferred via the food web in the same catchment ecosystem, the primary pathway was found to be the food chains originating from leaf and wood detritus, which was highly contaminated with radiocesium. Additionally, it was found that the decrease in ${ }^{137} \mathrm{Cs}$ concentration was through trophic interactions, which was suggestive of biological dilution and not the accumulation of ${ }^{137}$ Cs (Murakami et al. 2014).

During the past 4 years, while the total radiocesium accumulation has continuously decreased, its redistribution has proceeded by active transfers among compartments, such as transferring from canopy to litter layers on the forest floor. To develop a long-term future perspective in forest management, it is important to prepare a spatiotemporal prediction of radiocesium accumulation in the forest ecosystem. The aim of this paper is to summarize the time sequential changes in ${ }^{137} \mathrm{Cs}$ accumulation in major compartments of the forest ecosystem and to discuss the mechanism behind the estimation of the catchment-scale environmental half-life of ${ }^{137} \mathrm{Cs}$ accumulation.

\subsection{Material and Method}

\subsubsection{Study Site}

The study site was located at the headwater part of the Kami-Oguni River catchment in Date City, Fukushima prefecture, about $50 \mathrm{~km}$ northwest of the stricken nuclear power station (Fig. 13.1). Mean annual temperature in this region was $13{ }^{\circ} \mathrm{C}$ in 2012-2013 (Japan Meteorological Agency, 2012-2013), and the annual precipitation was $912 \mathrm{~mm}$ in 2012-2013 in this study site. Snow accumulation was observed every year, but annual maximum snow depth has been less than $60 \mathrm{~cm}$ during the period 1961-2017.

The monitoring catchment (18.9 ha) has been set at the headwater part of the Kami-oguni river. The catchment is mainly covered by second-growth forests consisting mainly of deciduous tree species (e.g. Quercus serrata, Acer pictum, Zelkova serrata, etc.). Some Japanese red pines (Pinus densiflora) were found at the ridge 


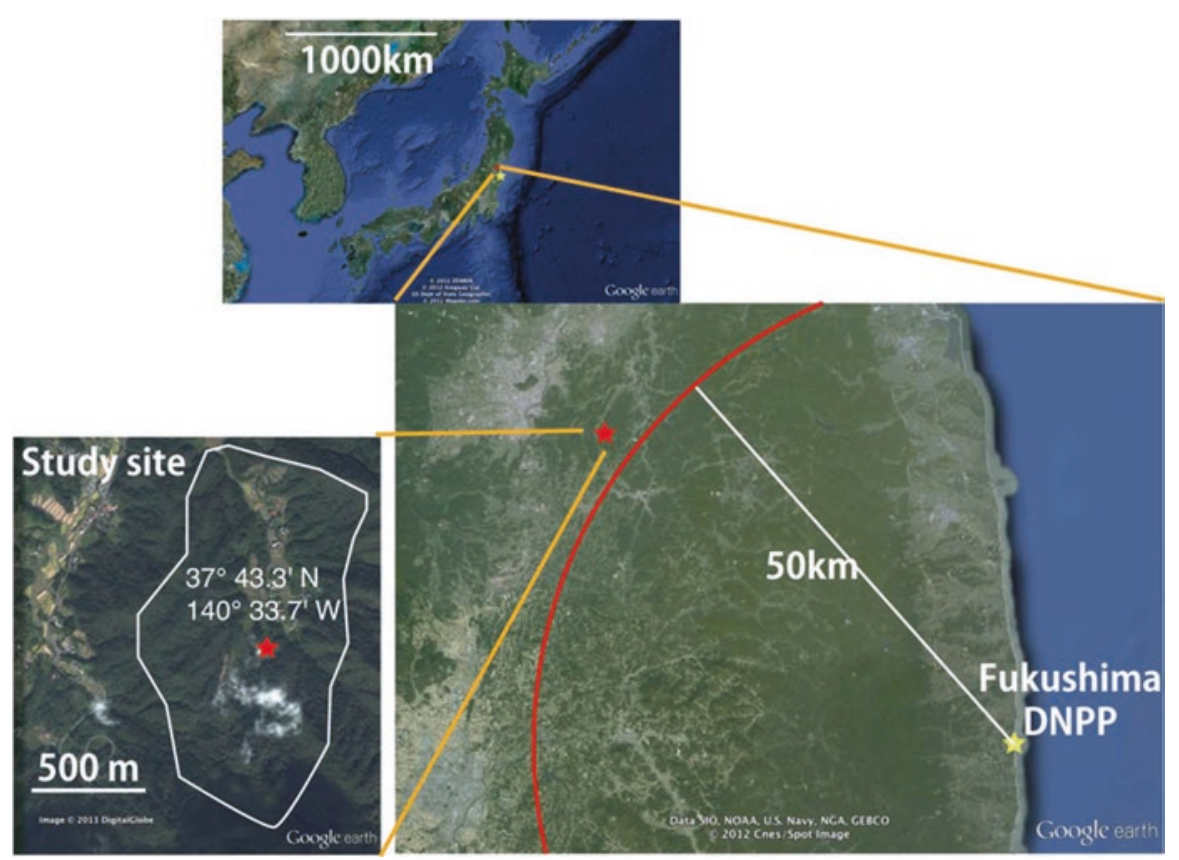

Fig. 13.1 Maps indicating the location of the study site at the Kami-Oguni River catchment. The study area was delineated with the geographic coordinates. These maps were attributed to Zenrin, Kingway Ltd., US Dept. of State Geographer, Mapabc.com, DATA SIO, NOAA, U.S. Navy, NGA, GEBCO, Cnes/Spot Image, and DigitalGlobe. (After Murakami et al. 2014)

part of the catchment. Deciduous trees in the second-growth forest have traditionally been utilized for charcoal and firewood production. Tree density of the second growth forests varied from 800 to 1300 ind. ha ${ }^{-1}$. Additionally, Japanese cedar (Cryptmeria japonica) plantations for timber production are situated at the lower part of the hill slopes. The age of the cedar plantation was about 50 years old; the stand density was 2100 ind. ha ${ }^{-1}$.

Two rectangular plots $(20 \times 20 \mathrm{~m})$ in the second growth forest dominated by $Q$. serrata and one plot $(10 \times 40 \mathrm{~m})$ in the Japanese cedar plantation was prepared for the vegetation survey. The height and diameter of all trees (at breast height) were measured to estimate the above-ground vegetation biomass.

According to a radioactivity survey report using an airborne survey device, the air dose rate and estimated ${ }^{137} \mathrm{Cs}$ deposition were $1.9-3.8 \mu \mathrm{Sv} \mathrm{h}^{-1}$ and 100 $300 \mathrm{kBq} \mathrm{m}^{-2}$ in August 2011, respectively, which was 5 months after the accident. The dose rate has decreased to $0.5-1.0 \mu \mathrm{Sv} \mathrm{h}^{-1}$ at (Ministry of Education, Culture, Sports, Science and Technology Japan 2017). 


\subsubsection{Sampling and ${ }^{137}$ Cs Concentration Measurements}

To determine ${ }^{137} \mathrm{Cs}$ accumulation in the major compartments of the target forest ecosystem, litter, soil and trees were sampled in May, July and September of each year from 2012 to 2015. Terrestrial and aquatic organisms including fungi, grasses, insects, soil worms, birds and small mammals were also sampled and had their ${ }^{137} \mathrm{Cs}$ content measured at the same time. Because these terrestrial and aquatic organisms' area-based biomasses were very small, we considered that their accumulation of ${ }^{137} \mathrm{Cs}$ would be negligible for the catchment scale discussion. Thus, we defined the major compartments of the forest catchment for discussions on ${ }^{137} \mathrm{Cs}$ redistribution within this ecosystem (Fig. 13.2).

All samples were dried for more than $48 \mathrm{~h}$ at $60{ }^{\circ} \mathrm{C}$ and powdered using a mortar and pestle. At least $200 \mathrm{mg}$ of each sample was collected and ${ }^{137} \mathrm{Cs}$ concentration was measured.

Litter and soil samples were collected from three points in the Q. serrata dominated stands and from two points in the $C$. japonica stands. Litter was separately sampled from the $\mathrm{L}, \mathrm{F}$ and $\mathrm{H}$ horizons of the organic layer using a square frame $(20 \times 20 \mathrm{~cm}, 15 \times 15 \mathrm{~cm}$ or $10 \times 10 \mathrm{~cm})$. Soil samples were taken from horizons at depths of $0-5 \mathrm{~cm}, 5-10 \mathrm{~cm}$ and $10-15 \mathrm{~cm}$.

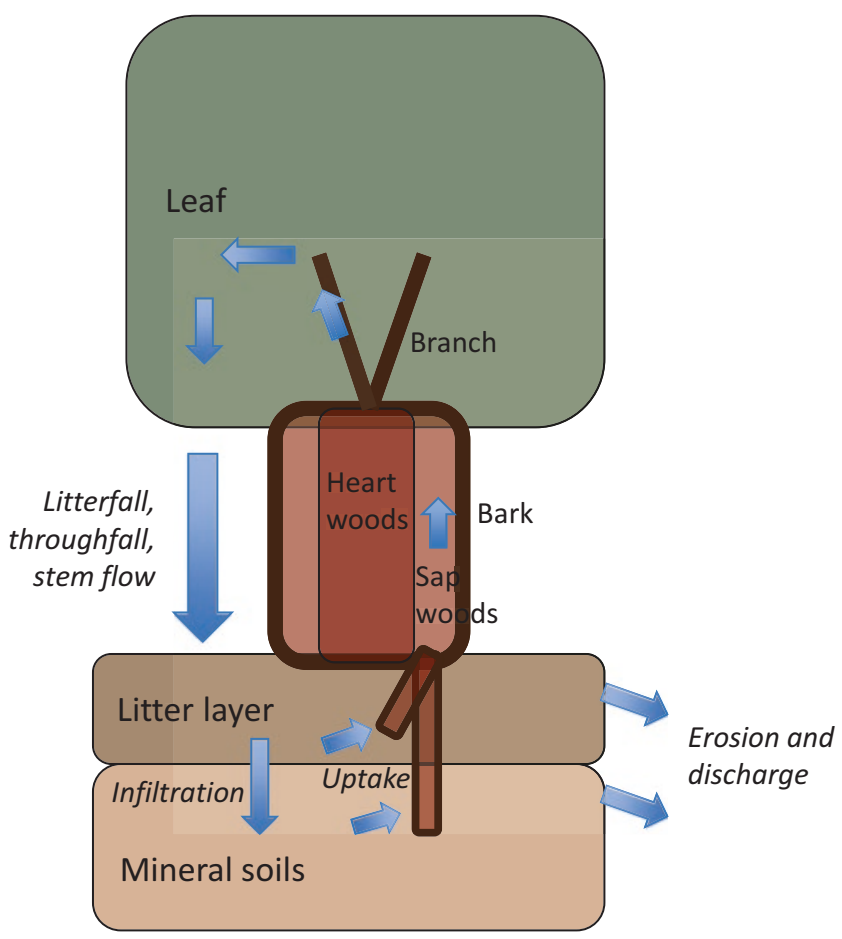

Fig. 13.2 Sampled substances for determining the ${ }^{137} \mathrm{Cs}$ distribution and redistribution mechanisms (in Italics) 
As tall trees in the stand were dominated by $Q$. serrata, two individuals of $Q$. serrata were cut down each year from 2012 to 2014 (one individual for 2015). One individual of $C$. japonica was also cut down from the $C$. japonica stands every year from 2012 to 2015. Leaves, branches, bark and wood (heartwood and sapwood) were sampled at every $2 \mathrm{~m}$ from the root side of sampled trees.

Gamma-ray spectrometry was conducted using germanium semiconductor detectors (Seiko EG\&G) for ${ }^{137} \mathrm{Cs}$ concentration measurements of all samples. An efficiency calibration of the detectors was made using volume radioactivity standard gamma sources (MX0333U8, Japan Radioisotope Association). Measuring accuracy was confirmed with the standard reference material JSAC-0471 (the Japan Society for Analytical Chemistry). The measured values were corrected for sampling day.

\subsubsection{Estimation of ${ }^{137}$ Cs Accumulation and Its Environmental Half-Life}

For litter layers and soil on the forest floor, the ${ }^{137} \mathrm{Cs}$ accumulation value of each compartment $\left(\mathrm{Bq} \mathrm{m}^{-2}\right)$ was estimated by multiplying the ${ }^{137} \mathrm{Cs}$ concentration value by the dry weight of each sample and then dividing by the sampling area (the square frame for sampling).

Dry weight biomass of each tree part (i.e., leaves, branches, bark, heartwood and sapwood) was estimated from the vegetation survey using allometry equations developed for the forests in Fukushima and proposed by Kajimoto et al. (2014) and Hosoda et al. (2010). Then, the area based ${ }^{137} \mathrm{Cs}$ accumulation as tree biomass $\left(\mathrm{Bq} \mathrm{m}^{-2}\right)$ was estimated by multiplying the average ${ }^{137} \mathrm{Cs}$ concentration value with the dry weight of each component.

For estimation of total accumulation in the study catchment, we calculated the areal ratios of the $Q$. serrata dominated stands, the $C$. japonica stands and stream channels from the aerial photo image of the catchment. Then, the area-based accumulation of each compartment was estimated.

\subsection{Results}

\subsubsection{Annual Changes of ${ }^{137}$ Cs Accumulation in Litter Layers, Soils and Trees}

The total accumulation of ${ }^{137} \mathrm{Cs}$ in forest floors decreased during the period 2012 2015 at both the $C$. japonica plantation and at the $Q$. serrata dominated stands (Fig. 13.3), while the initial distribution was significantly different between the two stands. This was because the deciduous trees had not leafed out when the accident 

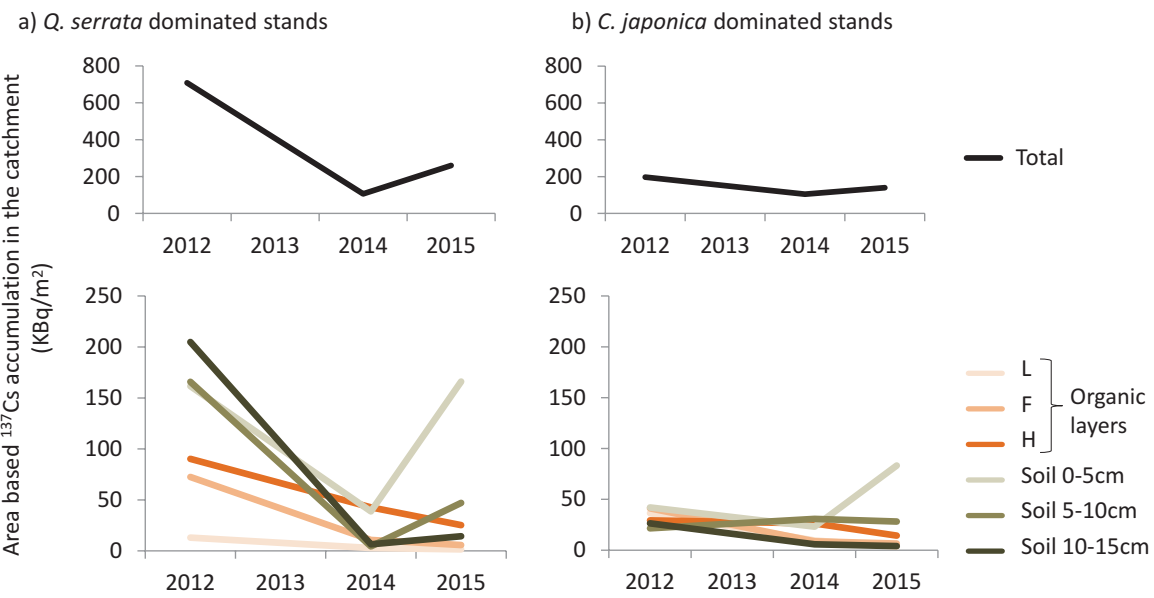

Fig. 13.3 Area based ${ }^{137} \mathrm{Cs}$ accumulation of litter layers and soil profile in (a) the $Q$. serrata dominated stands, and (b) the C. japonica dominated stands. (After Miyata 2017)

occurred in March 2011. ${ }^{137} \mathrm{Cs}$ accumulation in the litter layer of the cedar plantation site in 2012 was approximately $60 \%$ of that in the Q. serrata dominated stands (Fig. 13.3). This indicated that the canopies of the cedar trees captured ${ }^{137} \mathrm{Cs}$ deposition effectively. While significant decreases were found in most layers from 2012 to 2014 at both stands, ${ }^{137} \mathrm{Cs}$ accumulation in soils at a depth of $0-5 \mathrm{~cm}$ increased during 2014-2015.

While the ${ }^{137} \mathrm{Cs}$ accumulation was greater in the fresh leaves of the canopy than the other parts of the C. japonica tree, it was greater in the bark for the Q. serrata dominated stands (Fig. 13.4). The ${ }^{137} \mathrm{Cs}$ accumulation in the cedar bark was significantly lower than that of $Q$. serrata. This indicated that the dense canopy of the cedar trapped the ${ }^{137} \mathrm{Cs}$ deposition effectively and reduced the amount of deposition detected beneath the canopy.

It was notable that ${ }^{137} \mathrm{Cs}$ accumulation in the heartwood and sapwood increased gradually during the period of 2012-2015, although the total accumulation of ${ }^{137} \mathrm{Cs}$ in the bodies of trees decreased (Fig. 13.4).

\subsubsection{Changes in ${ }^{137}$ Cs Accumulation in Each Compartment of the Catchment}

Since $2012,{ }^{137} \mathrm{Cs}$ accumulation in most compartments decreased significantly in this catchment, except in surface soils and in heartwood and sapwood (Fig. 13.5). The largest accumulation has continuously existed in the litter layer and the nearsurface mineral soils $(0-15 \mathrm{~cm})$. About $90 \%$ of total ${ }^{137} \mathrm{Cs}$ accumulation of the catchment was held in the forest floor, and about $10 \%$ of that was retained in the 
a) Q. serrata dominated stands

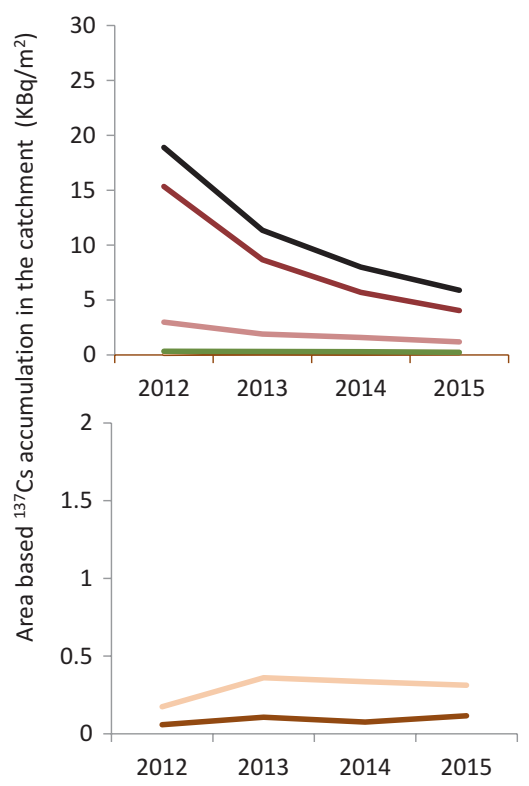

b) C. japonica dominated stands

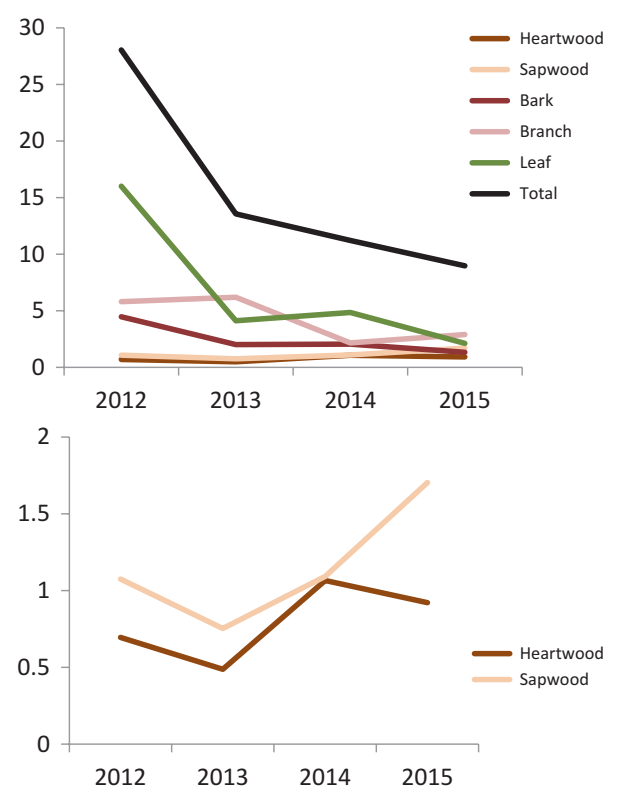

Fig. 13.4 Area based ${ }^{137} \mathrm{Cs}$ accumulation within the tree body in (a) the $Q$. serrata dominated stands, and (b) the $C$. japonica dominated stands. Close-up on the changes of ${ }^{137} \mathrm{Cs}$ accumulation in the heartwood and sapwood of both stands were also shown. (After Miyata 2017)

above-ground living tree biomass. While the total accumulation has decreased onesixth between 2012 and 2014, the proportion of the accumulation in the shallow mineral soils $(0-5 \mathrm{~cm})$ has increased during the same period. The accumulation itself has also increased in the 5-10 cm soils during 2014-2015 (Fig. 13.5).

\subsection{Discussion}

\subsubsection{Redistribution of the ${ }^{137}$ Cs Accumulation}

The increase in ${ }^{137} \mathrm{Cs}$ accumulation in wood parts for both $Q$. serrata and $C$. japonica stands (Fig. 13.4) indicated that circulation occurred between trees and soils. ${ }^{137} \mathrm{Cs}$ in the tree body was transported to leaves, and then it moved to the forest floor through litterfall. Decomposition of litterfalls releases ${ }^{137} \mathrm{Cs}$ into the root zone within the organic and shallow mineral soil layers. This ${ }^{137} \mathrm{Cs}$ could be absorbed by trees through their root system. This cycle has acted as a retention system of ${ }^{137} \mathrm{Cs}$ in the forest.

At the interface between the litter layer and mineral soils, ${ }^{137} \mathrm{Cs}$ has moved down from the $\mathrm{H}$ horizon to the surface part of the mineral soils in recent years (Fig. 13.3). 


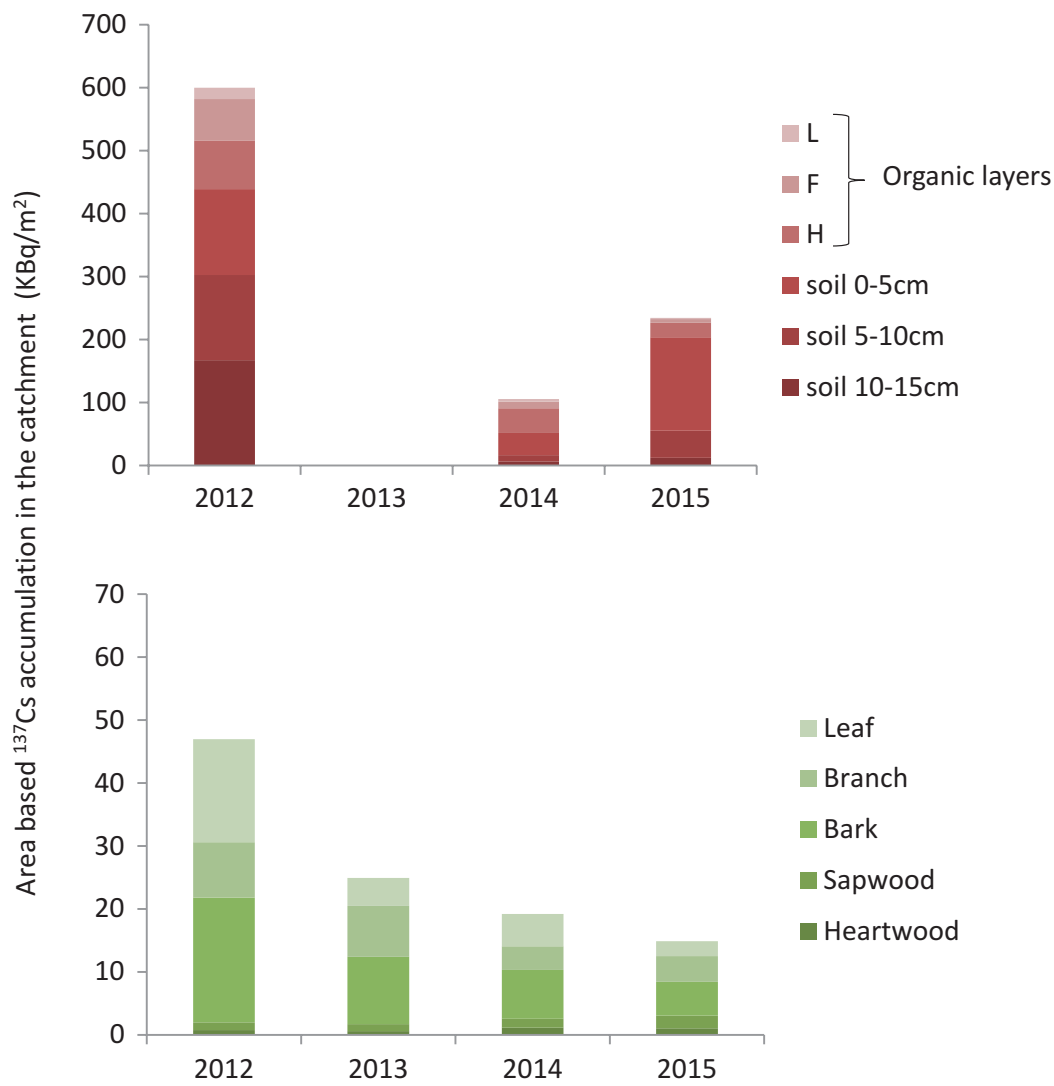

Fig. 13.5 Area based ${ }^{137} \mathrm{Cs}$ accumulation in organic layers, soil horizons (upper panel) and aboveground biomass (lower panel) in the study catchment including both the $Q$. serrata dominated stands and the $C$. japonica dominated stands. (After Miyata 2017)

Significant increases in ${ }^{137} \mathrm{Cs}$ accumulation in soil depths of $0-5 \mathrm{~cm}$ during 2014 2015 could partly be explained by this mechanism. However, other accumulation mechanisms are required to be able to fully understand this drastic increase. One of the possible mechanisms was lateral input from the upslope parts onto the actual sampling points. Drifting of litter, for example, from upslope can supply extra ${ }^{137} \mathrm{Cs}$ in addition to the vertical movement.

Several surveys have previously been conducted on the slope movement of deposited ${ }^{137} \mathrm{Cs}$ and it was found that the movement with drifting litter and surface soil occurred occasionally by surface water flows and drifting snow accumulation (Kashihara 2014; Takada et al. 2017). As the soil layer for most of the catchment was established on the slopes, the ${ }^{137} \mathrm{Cs}$ movement with drifting litter along hill slopes still needs to be researched quantitatively to estimate the catchment scale ${ }^{137} \mathrm{Cs}$ accumulation precisely. 


\subsubsection{Catchment-Scale Environmental Half-Life of the ${ }^{137} \mathrm{Cs}$ Accumulation}

The environmental half-life of ${ }^{137} \mathrm{Cs}$ accumulation in the entire catchment ecosystem was estimated from the fitted curve applied to yearly change based on the data in Fig. 13.4; the half-life was estimated to be about 2 years since July 2012 when the survey was initiated. This estimation was significantly shorter than the physical half-life of ${ }^{137} \mathrm{Cs}$, because of the washout effect on the deposited ${ }^{137} \mathrm{Cs}$ in the first few years immediately after the accident. After 2014, the annual discharge of ${ }^{137} \mathrm{Cs}$ through stream flow from this catchment was estimated to be 2-3 orders of magnitude lower than the initial deposited amount of ${ }^{137} \mathrm{Cs}$ in this area (Iseda 2015). It was clear that the rate of decrease in ${ }^{137} \mathrm{Cs}$ accumulation in watershed has further declined since then.

\subsection{Perspective}

The internal ${ }^{137} \mathrm{Cs}$ cycle among the soil-plant system was clearly identified as a retention mechanism and was biologically dynamic. The increasing trend of ${ }^{137} \mathrm{Cs}$ in sapwood and heartwood of $Q$. serrata has slowed. This might indicate that the ${ }^{137} \mathrm{Cs}$ cycle between trees and soils was approaching a steady state condition.

Currently, the fixation with clay mineral in soils and the biological retention by the internal cycle among soil and plants are major factors retaining ${ }^{137} \mathrm{Cs}$ in this forest catchment. Mechanisms that decrease ${ }^{137} \mathrm{Cs}$ accumulation are the occasional discharge through streams via soil and litter particles during storm events, and physical decay. It is essential to continue to monitor the decreasing and retaining mechanisms carefully at the ecosystem level, because this information will be needed for careful consideration on radioactivity controls in forest and water resources management.

Acknowledgement All data were collected during a research projects supported by a grant (24248027, 16H04934) for scientific research from the Ministry of Education, Culture, Sports, Science and Technology and with a grant for environmental researches from The Sumitomo Foundation. The authors would like to thank Mr. Chonosuke Watanabe for his kind help during the field work.

\section{References}

Bunzl K, Schimmack W, Kreutzer K, Schierl R (1989) Interception and retention of Chernobylderived ${ }^{134} \mathrm{Cs},{ }^{137} \mathrm{Cs}$ and ${ }^{106} \mathrm{Ru}$ in a spruce stand. Sci Total Environ $78: 77-87$. https://doi. org/10.1016/0048-9697(89)90023-5

Chino M, Nakayama H, Nagai H, Terada H, Katata G, Yamazawa H (2011) Preliminary estimation of release amounts of ${ }^{131} \mathrm{I}$ and ${ }^{137} \mathrm{Cs}$ accidentally discharged from the Fukushima Daiichi 
nuclear power plant into the atmosphere. J Nucl Sci Technol 48:1129-1134. https://doi.org/10 $.1080 / 18811248.2011 .9711799$

Endo I, Ohte N, Iseda K, Tanoi K, Hirose A, Kobayashi NI, Murakami M, Tokuchi N, Ohashi M (2015) Estimation of radioactive 137-cesium transportation by litterfall, stemflow and throughfall in the forests of Fukushima. J Environ Radioact 149:176-185. https://doi.org/10.1016/j. jenvrad.2015.07.027

Fukushima Prefecture (2017) Forests of Fukushima. in Division of Forest Planning, editor. Fukushima Prefecture, Fukushima. http://www.pref.fukushima.lg.jp/sec/36055a/shinrinkeikaku.html (referred on 2017/07/28)

Fukuyama T, Takenaka C, Onda Y $(2005){ }^{137} \mathrm{Cs}$ loss via soil erosion from a mountainous headwater catchment in Central Japan. Sci Total Environ 350:238-247. https://doi.org/10.1016/j. scitotenv.2005.01.046

Hashimoto S, Ugawa S, Nanko K, Shichi K (2012) The total amounts of radioactively contaminated materials in forests in Fukushima, Japan. Sci Rep 2. https://doi.org/10.1038/srep00416

Hashimoto S, Matsuura T, Nanko K, Linkov I, Shaw G, Kaneko S (2013) Predicted spatio-temporal dynamics of radiocesium deposited onto forests following the Fukushima nuclear accident. Sci Rep 3. https://doi.org/10.1038/srep02564

Hisadome K, Onda Y, Kawamori A, Kato H (2013) Migration of radiocaesium with litterfall in hardwood-Japanese red pine mixed forest and sugi plantation. J Jpn Soc 95:267-274 (In Japanese with English abstract)

Hosoda K, Mitsuda Y, Iehara T (2010) Differences between the present stem volume tables and the values of the volume equations, and their correction. Jpn J For Plan 44:23-39 (in Japanese)

Iseda K (2015) Study on changes in discharge forms of ${ }^{137} \mathrm{Cs}$ from a forest catchment in northern Fukushima using information on mechanisms of suspended solid discharge. University of Tokyo, Tokyo (in Japanese)

Japan Meteorological Agency Japan (2017) Tables of Monthly Climate Statistics. http://www. data.jma.go.jp/obd/stats/data/en/smp/index.html, Japan Meteoro- logical Agency (referred on 2017/0728)

Kajimoto T, Takano T, Saito T, Kuroda K, Fujiwara K, Komatsu M, Kawasaki T, Ohashi S, Seino $Y$ (2014) Methods for assessing the spatial distribution and dynamics of radiocesium in tree components in forest ecosystems. Bull FFPRI 13:113-136 (in Japanese)

Kashihara M (2014) Changes in spatial distribution of radiocesium deposited from the nuclear power plant accident with surface soil movement in a forest of Fukushima. Graduation thesis of University of Tsukuba, Tsukuba, Japan (in Japanese)

Kato H, Onda Y, Gomi T (2012) Interception of the Fukushima reactor accident-derived ${ }^{137} \mathrm{Cs}$, ${ }^{134} \mathrm{Cs}$ and ${ }^{131} \mathrm{I}$ by coniferous forest canopies. Geophys Res Lett 39:L20403. https://doi. org/10.1029/2012GL052928

Kinnersley RP, Goddard AJH, Minski MJ, Shaw G (1997) Interception of caesium-contaminated rain by vegetation. Atmos Environ 31:1137-1145. https://doi.org/10.1016/S1352-2310(96)00312-3

Kitchings T, Digregorio D, P Van Voris (1976) A review of ecological parameters in vertebrate food chains. In: Proceedings of the fourth national symposium on radioecology. Ecological Society of America, Oregon State University, Corvallis, Oregon, pp 304-313

Kruyts N, Delvaux B (2002) Soil organic horizons as a major source for radiocesium biorecycling in forest ecosystems. J Environ Radioact 58:175-190. https://doi.org/10.1016/ s0265-931x(01)00065-0

Ministry of Education, C., Sport, Science and Technology and Ministry of Ministry of Agriculture, Forestry and Fisheries (2012) Study report on distribution of radioactive substances emitted by the accident of the Fukushima Daiichi Nuclear Power Plant. Tokyo

Ministry of Education, C., Sports, Science and Technology Japan (2017) Extension site of the distribution map for radiation dose. http://ramap.jmc.or.jp/map/. Ministry of Education, Culture, Sports, Science and Technology Japan (referred on 2017/07/28)

Miyata T (2017) Inventory estimation of 137Cs in a forested ecosystem originates from the nuclear power plant accident. Master thesis of graduate School of Science, Chiba University, Chiba, Japan (in Japanese) 
Murakami M, Ohte N, Suzuki T, Ishii N, Igarashi Y, Tanoi K (2014) Biological proliferation of cesium-137 through the detrital food chain in a forest ecosystem in Japan. Sci Rep 4. https:// doi.org/10.1038/srep03599

Ohte N, Murakami M, Iseda K, Tanoi K, Ishii N (2013) Diffusion and transportation dynamics of ${ }^{137} \mathrm{Cs}$ deposited on the forested area in Fukushima after the nuclear power plant accident in March 2011. In: Nakanishi T, Tanoi K (eds) Agricultural implications of the Fukushima nuclear accident. Springer, New York, pp 177-186

Ohte N, Murakami M, Endo I, Ohashi M, Iseda K, Suzuki T, Oda T, Hotta N, Tanoi K, Kobayashi NI, Ishii N (2016) Ecosystem monitoring of radiocesium redistribution dynamics in a forested catchment in Fukushima after the nuclear power plant accident in March 2011. In: Nakanishi TM, Tanoi K (eds) Agricultural implications of the Fukushima nuclear accident: the first three years. Springer, Tokyo, pp 175-188

Rowan DJ, Rasmussen JB (1994) Bioaccumulation of radiocesium by fish: the influence of physicochemical factors and trophic structure. Can J Fish Aquat Sci 51:2388-2410. https://doi. org/10.1139/f94-240

Schimmack W, Förster H, Bunzl K, Kreutzer K (1993) Deposition of radiocesium to the soil by stemflow, throughfall and leaf-fall from beech trees. Radiat Environ Biophys 32:137-150. https://doi.org/10.1007/BF01212800

Steinhauser G, Brandl A, Johnson TE (2014) Comparison of the Chernobyl and Fukushima nuclear accidents: a review of the environmental impacts. Sci Total Environ 470:800-817. https://doi. org/10.1016/j.scitotenv.2013.10.029

Takada M, Yamada T, Takahara T, Endo S, Tanaka K, Kajimoto T, Okuda T (2017) Temporal changes in vertical distribution of ${ }^{137} \mathrm{Cs}$ in litter and soils in mixed deciduous forests in Fukushima, Japan. J Nucl Sci Technol 54:452-458. https://doi.org/10.1080/00223131.2017. 1287602

Wakiyama Y, Onda Y, Mizugaki S, Asai H, Hiramatsu S (2010) Soil erosion rates on forested mountain hillslopes estimated using ${ }^{137} \mathrm{Cs}$ and ${ }^{210} \mathrm{~Pb}_{\mathrm{ex}}$. Geoderma 159:39-52. https://doi. org/10.1016/j.geoderma.2010.06.012

Wang WX, Ke C, Yu KN, Lam PKS (2000) Modeling radiocesium bioaccumulation in a marine food chain. Mar Ecol Prog Ser 208:41-50

Open Access This chapter is licensed under the terms of the Creative Commons Attribution 4.0 International License (http://creativecommons.org/licenses/by/4.0/), which permits use, sharing, adaptation, distribution and reproduction in any medium or format, as long as you give appropriate credit to the original author(s) and the source, provide a link to the Creative Commons license and indicate if changes were made.

The images or other third party material in this chapter are included in the chapter's Creative Commons license, unless indicated otherwise in a credit line to the material. If material is not included in the chapter's Creative Commons license and your intended use is not permitted by statutory regulation or exceeds the permitted use, you will need to obtain permission directly from the copyright holder.

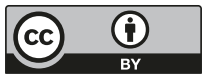

